\title{
Effects of alanyl-glutamine supplementation on the small intestinal mucosa barrier in weaned piglets
}

\author{
Shen Xing ${ }^{1}$, Bolin Zhang ${ }^{1,2}$, Meng Lin', Ping Zhou', Jiaolong Li', Lin Zhang ${ }^{1}$, Feng Gao ${ }^{1, *}$, and Guanghong Zhou ${ }^{1}$
}

* Corresponding Author: Feng Gao Tel: +86-25-84399007, Fax: +86-25-84395314,

E-mail: gaofeng0629@sina.com

'College of Animal Science and Technology, Key Laboratory of Animal Origin Food Production and Safety Guarantee of Jiangsu Province, Jiangsu Collaborative Innovation Center of Meat Production and Processing, Quality and Safety Control, Nanjing Agricultural University, Nanjing 210095, China 2 Department of Agricultural Science and Technology, Zunyi Normal College, Zunyi 563002, China

Submitted Jan 27, 2016; Revised Apr 27, 2016; Accepted Jun 28, 2016
Objective: The study was to investigate the effects of alanyl-glutamine (Ala-Gln) and glutamine (Gln) supplementation on the intestinal mucosa barrier in piglets.

Methods: A total of 180 barrows with initial weight $10.01 \pm 0.03 \mathrm{~kg}$ were randomly allocated to three treatments, and each treatment consisted of three pens and twenty pigs per pen. The piglets of three groups were fed with control diet [0.62\% alanine (Ala)], Ala-Gln diet (0.5\% Ala-Gln), Gln diet ( $0.34 \%$ Gln and $0.21 \% \mathrm{Ala})$, respectively.

Results: The results showed that in comparison with control diet, dietary Ala-Gln supplementation increased the height of villi in duodenum and jejunum ( $\mathrm{p}<0.05)$, Gln supplementation increased the villi height of jejunum $(\mathrm{p}<0.05)$, Ala-Gln supplementation up-regulated the mRNA expressions of epidermal growth factor receptor and insulin-like growth factor 1 receptor in jejunal mucosa $(\mathrm{p}<0.05)$, raised the mRNA expressions of Claudin-1, Occludin, zonula occludens protein-1 (ZO-1) and the protein levels of Occludin, ZO-1 in jejunal mucosa $(\mathrm{p}<0.05)$, Ala-Gln supplementation enlarged the number of goblet cells in duodenal and ileal epithelium ( $\mathrm{p}<0.05)$, Gln increased the number of goblet cells in duodenal epithelium $(\mathrm{p}<0.05)$ and Ala-Gln supplementation improved the concentrations of secretory immunoglobulin $A$ and immunoglobulin $G$ in the jejunal mucosa $(\mathrm{p}<0.05)$.

Conclusion: These results demonstrated that dietary Ala-Gln supplementation could maintain the integrity of small intestine and promote the functions of intestinal mucosa barriers in piglets.

Keywords: Alanyl-glutamine, Glutamine, Small Intestine, Mucosa Barrier, Piglet

\section{INTRODUCTION}

Small intestine is the main location of nutrient digestion and absorption in the body owing to its special structures and complex physiological functions. Meanwhile, as the boundary of the external and internal environment in body, the intestinal epithelium works as a barrier to prevent foreign pathogens and toxins from adhering and colonizing the intestinal tissue. In addition, the intestinal epithelium can secrete some specific and nonspecific immune substances, which constitute significant components of the body's immune barrier [1]. The intestinal mucosa barriers are divided into four types according to their structure characteristics; including the physical barrier, chemical barrier, immune barrier and microbial barrier [2]. Each barrier has the unique physiological function and coordinates with the others to maintain the overall intestinal mucosa barrier function.

During the primary stage of piglet's development, the nutrients in meals cannot be fully digested or absorbed because of intestinal hypoplasia, which may result in the malnutrition. In addition, the sensitive intestine will be stimulated by exogenous deleterious factors resulting in stress damage. Therefore, nutrition regulation and drug management in this stage are critical

\section{www.ajas.info}


to maintain intestinal health in piglets.

Glutamine (Gln) is in the highest concentration of all amino acids in blood and milk in mammals and which has been considered to be the provider carbon source for the synthesis of purines and pyrimidines and involved in the Krebs cycle via generating a-ketoglutaric acid through deamination and transamination procedures [3]. What's more, Gln is the important fuel for intestinal epithelial cell proliferation and integrity repair. The endogenous Gln of the body is inadequate when the piglets experience stress and is required to be supplemented in the diet. However, the utilization rate of free Gln in diets is low. Alanyl-glutamine (Ala-Gln) dipeptide is more stable and dissolvable than free Gln, and is recommended to be a substitute for Gln monomers [4]. Previous findings in our lab showed that the diet supplemented with Ala-Gln could improve the growth performance of piglets [5]. But so far, the molecular mechanisms of Ala-Gln and Gln in regulating the small intestinal mucosa barrier are poorly understood. Therefore, the objectives of the present experiment were to investigate the effects of dietary Ala-Gln and Gln supplementation on intestinal mucosa barrier in piglets.

\section{MATERIALS AND METHODS}

\section{Animals and experimental design}

Standard operating procedures for animal care were approved by the Institutional Animal Care and Use Committee of Nanjing Agricultural University. One hundred and eighty crossed barrows (Duroc $\times$ Large White $\times$ Landrace, aged $35 \pm 1$ days) with the average body weight of $10.01 \pm 0.03 \mathrm{~kg}$ were randomly allocated to three treatments, and each treatment consisted of three pens and twenty pigs per pen. The piglets of three groups were fed with the control diet (basal diet added $0.62 \%$ alanine [Ala]), Ala-Gln diet (basal diet added 0.5\% Ala-Gln) and Gln diet (basal diet added $0.34 \%$ Gln and $0.21 \%$ Ala), respectively. The dosage of $0.5 \%$ Ala-Gln was chosen based on previous study [6]. The control diet and Gln diet were supplemented with $0.62 \%$ or $0.21 \%$ Ala to obtain isonitrogenous diet as in previous experiments [7]. The diets were formulated according to the energy and amino acid requirements of piglets recommended by the National Research Council [8]. The nutrient composition was calculated according to the recommendations of "Chinese Feed Database" [9], the crude protein (CP) of diets was measured with a nitrogen gas analyzer utilizing procedure [10] and the ingredients of the basal diets are shown in Table 1. The materials of Ala, Gln, and Ala-Gln were obtained from Tian Chen Pharmaceutical Co. (Tianjin, China).

The piglets were allowed a 3-days adjustment period before the formal experiment. All the piglets were housed in an environmentally controlled building during the whole experiment, and had ad libitum access to feed and water, the room temperature was maintained at $25^{\circ} \mathrm{C}$ to $27^{\circ} \mathrm{C}$. The duration of the
Table 1. Ingredients and nutrients content of the basal diets (as-fed basis)

\begin{tabular}{lclc}
\hline Ingredients (\%) & \multicolumn{3}{l}{ Nutrients content } \\
\hline Ground corn & 49.50 & Crude protein (\%) & 19.96 \\
Wheat flour & 11.06 & Calcium (\%) & 0.70 \\
Soybean meal & 19.30 & Available phosphorus (\%) & 0.33 \\
Expanded soybean & 9.50 & Net energy (MJ/kg) & 10.13 \\
Whey powder & 5.00 & Lysine (\%) & 1.24 \\
Fish meal & 2.50 & Methionine+Cysteine (\%) & 0.69 \\
DL- methionine & 0.11 & Threonine (\%) & 0.74 \\
L-Lysine -HCl & 0.37 & Tryptophan (\%) & 0.21 \\
L-Threonine & 0.11 & Arginine (\%) & 1.15 \\
Dicalcium phosphate & 0.62 & Histidine (\%) & 0.43 \\
Limestone powder $_{\text {Sodium chloride }}$ & 0.63 & Isoleucine (\%) & 0.71 \\
Vitamin and mineral premix $^{11)}$ & 0.30 & Leucine (\%) & 1.41 \\
Ala $^{2)}$ & 1.00 & Phenylalanine (\%) & 0.81 \\
Ala-Gln $^{3)}$ & 0.62 & Valine (\%) & 0.78 \\
Ala $^{4)}$ & 0.50 & & \\
Gln $^{4)}$ & 0.21 & & \\
\hline
\end{tabular}

1) Premix provide per $\mathrm{kg}$ of diet provided: retinyl acetate, 11,000 IU; cholecalciferol, 2,000 IU; DL-a-tocopheryl acetate, $30 \mathrm{IU}$; menadione sodium bisulphite, $4.4 \mathrm{mg}$; thiamin mononitrate, $1.5 \mathrm{mg}$; riboflavin, $6 \mathrm{mg}$; pyridoxine hydrochloride, $3 \mathrm{mg}$; cyanocobalamin, $3.2 \mathrm{mg}$; D-pantothenic acid, $15 \mathrm{mg}$; nicotinic acid, $33 \mathrm{mg}$; D-biotin, 0.20 $\mathrm{mg}$; folic acid, $1.65 \mathrm{mg}$; choline, $500 \mathrm{mg} ; 150 \mathrm{mg}$ of iron as iron sulphate; $171.5 \mathrm{mg}$ of copper as copper sulphate; $109.5 \mathrm{mg}$ of zinc as zinc oxide; $32 \mathrm{mg}$ of manganese as manganous oxide; $0.45 \mathrm{mg}$ of selenium as sodium selenite; $0.40 \mathrm{mg}$ of iodine as calcium iodate.

${ }^{2)} \mathrm{Ala}$, the amount of Ala supplemented in control group.

${ }^{3)}$ Ala-Gln, the amount of Ala-GIn supplemented in Ala-GIn group.

${ }^{4)}$ Ala and ${ }^{4)} \mathrm{Gln}$, the amount of Ala and GIn supplemented in Gln group.

${ }^{5)}$ Nutrient content of the diets was the value of measurement.

experiment was 28 days. All the piglets were fed three times per day at 06:30, 11:00, and 18:00 hours.

\section{Collection of samples}

Six piglets were randomly selected from each treatment (two pigs per pen) based on the average body weight with 18 piglets in total for sampling. Piglets were euthanatized by cardiac injection of pentobarbital (50 mg/kg.body weight) and bled via jugular venipuncture. The abdominal wall was opened by a midline incision, the entire small intestine was exteriorized and divided into three segments. Approximately a $5 \mathrm{~cm}$ length of the middle portion of duodenum, jejunum and ileum were cut out, and fixed in 4\% paraformaldehyde to store for morphometric analysis. The three sections of the small intestine were each rinsed gently with sterile saline to clean out the contents, then the intestinal mucosa from each segment was carefully scraped off with a glass microscope slide, and snap-frozen in liquid $\mathrm{N}_{2}$ for the further analysis.

\section{Histology}

The segments of duodenum, jejunum and ileum $(5 \mathrm{~cm})$ which were fixed in paraformaldehyde were removed and embedded in paraffin, afterwards they were cut into approximately $5-\mathrm{mm}$ thick slices by microtome. After that, the slices were mounted 
on glass slides and stained with hematoxylin and eosin to observe intestinal histomorphology. In each slice, the height of villi (determined as the distance from the villus tip to the crypt mouth) and the associated depth of crypts (measured from the crypt mouth to the base) were measured through computeraided light microscope (Nikon, Tokyo, Japan). The mean of measurements was calculated to yield three values per piglet. On the other hand, other histologic sections were stained with periodic acid schiff and the number of goblet cells (determined as the ratio of the total of goblet cells to the total of columnar cells among whole villus and statistics of five villi per piglet) in the intestinal villi were counted. The images of goblet cells were captured using an Olympus BX51 microscope (Olympus Optical Co., Ltd, Tokyo, Japan), and then, those images were analysed via the computer-assisted morphometric system, the mean was calculated to yield 6 values per piglet. These procedures were also processed by an observer unaware of the dietary treatments.

\section{RNA extraction and complementary DNA (cDNA) synthesis}

The samples of jejunal mucosa were homogenized with the TRIzol reagent (Invitrogen, Carlsbad, CA, USA) to extract the total RNA and treated by DNase I (Invitrogen, Carlsbad, CA, USA) according to the manufacturer's guidelines. The OD260 and OD280 measurements of the RNAs were determinede spectrophotometrically (ND-1000, Nano Drop Technologies, Rockland, DE, USA). All samples presented the ratio of OD260/OD280 were 1.8 to 2.0, and the ratio of A260/A230 was 1.7 to 2.1. RNA was reverse transcribed to CDNA via a Prime Script 1st Strand cDNA Synthesis Kit (Takara, Ostu, Japan) according to the recommended by manufacturers. The program included $37^{\circ} \mathrm{C}, 15 \mathrm{~min} ; 85^{\circ} \mathrm{C}, 5 \mathrm{~s} ; 4^{\circ} \mathrm{C}$.

\section{Quantification of mRNA levels}

Real time-polymerase chain reaction (RT-PCR, SYBR Premix Ex Taq, catalogue no. RR420A) was performed in a total volume of $20 \mu \mathrm{L}$, and it contained $10 \mu \mathrm{L}$ SYBR Premix Ex Taq (2×), 0.4 $\mu \mathrm{L}$ forward and reverse primers, $0.4 \mu \mathrm{L}$ ROX Reference Dye (50x) and $2.0 \mu \mathrm{L} \mathrm{cDNA}$ according to the manufacturer's recommendations. RT-PCR program consisted of $30 \mathrm{~s}$ at $95^{\circ} \mathrm{C}, 40$ cycles of $5 \mathrm{~s}$ at $95^{\circ} \mathrm{C}$ and $34 \mathrm{~s}$ at $60^{\circ} \mathrm{C}$. All samples were analyzed systematically through their melting curve. Glyceraldehyde3-phosphate dehydrogenase (GAPDH) as an internal control was used to normalize the mRNA abundance of each sample according to the $2^{-\Delta \Delta C T}$ method [11]. The relative primers for target genes were designed with software (Oligo 6.0; Molecular Biology Insights, Cascade, CO, USA) and the sequences were listed in Table 2.

\section{Western blot analysis}

A portion of intestinal mucosa samples were removed from the liquid nitrogen and thawed on ice, mechanically homogenized soon afterwards and centrifuged at 10,000 g; $15 \mathrm{~min}$ at $4^{\circ} \mathrm{C}$, and then the supernatants collected. The total protein concentration of supernatants were measured via bicinchoninic acid assay protein assay kit (Sangon Biotec, Shanghai, China) and diluted to an appropriate concentration according to the

Table 2. Primer pairs used in the real time-polymerase chain reaction

\begin{tabular}{|c|c|c|c|}
\hline Genes & Sequences $\left(5^{\prime} \rightarrow 3^{\prime}\right)$ & Accession No. & Product size (bp) \\
\hline \multirow[t]{2}{*}{$E G F$} & Sense:ATGTCAACGAGTGTGCCTTC & NM_214020.1 & 106 \\
\hline & Antisense:TCAGGGAGCAGAACAAATCC & & \\
\hline \multirow[t]{2}{*}{ EGFR } & Sense:ATCTGTAACCCGCTGTGCTC & NM_214007.1 & 147 \\
\hline & Antisense:GGCATTCTCCACGAACTCTC & & \\
\hline \multirow[t]{2}{*}{ IGF-1 } & Sense:AACAAGCCCACAGGGTACG & NM_214256.1 & 100 \\
\hline & Antisense:TCTCCAGCCTCCTCAGATCA & & \\
\hline \multirow[t]{2}{*}{ MUC1 } & Sense:TGCACCATTTCCTTCCTCTG & AY_243508.1 & 143 \\
\hline & Antisense:AGTTCTTTCGTCGGCACTGA & & \\
\hline \multirow[t]{2}{*}{ MUC2 } & Sense:ACGACTTTGACGGACACTGCT & XM_002347185.2 & 116 \\
\hline & Antisense:AGGGGACGTTCTCGGTGAT & & \\
\hline Occludin & Sense:CAGTGGCTTTGGTGGCTATG & NM_001163647.2 & 101 \\
\hline & Antisense:GGGACCTGCTCATAACTTCG & & \\
\hline \multirow[t]{2}{*}{ GAPDH } & Sense:ATGGTGAAGGTCGGAGTGAAC & NM_001206359 & 235 \\
\hline & Antisense:CTCGCTCCTGGAAGATGGT & & \\
\hline
\end{tabular}

EGF, epidermal growth factor; EGFR, epidermal growth factor receptor; IGF-1, insulin-like growth factor 1; IGF-1R, insulin-like growth factor 1 receptor; MUC1, mucin 1; MUC2, mucin 2; ZO-1, zonula occludens protein-1; GAPDH, glyceraldehyde-3-phosphate dehydrogenase. 
operation instructions. Equal amounts of protein from each sample $(30 \mu \mathrm{g})$ were separated with sodium dodecyl sulfatepolyacrylamide gel electrophoresis on $10 \%$ (occludin and claudin-1) or 7.5\% (zonula occludens protein-1, ZO-1) polyacrylamide gel. The target proteins in the gel were transferred to polyvinylidene difluoride membranes. The membranes were soaked in 5\% nonfat milk in tris buffered saline with Tween-20 (TBST, $200 \mathrm{mM}$ Tris, $137 \mathrm{mM} \mathrm{NaCl}, 5 \mathrm{mM} \mathrm{KCl}$ and $0.1 \%$ Tween-20) for $2 \mathrm{~h}$ at room temperature, sequential incubated with primary antibody for occludin, claudin- 1 and ZO-1 (1:500, diluted with TBST) overnight at $4^{\circ} \mathrm{C}$ with gentle shaking. After that, the membranes were washed with TBST and incubated with horseradish peroxidase-conjugated secondary antibody (1:3,000, diluted with TBST) for $2 \mathrm{~h}$ at room temperature. The primary antibodies for occludin, claudin-1, $\mathrm{ZO}-1, \beta$-actin and the second antibody were purchased from Santa Cruz Biotechnology (Inc., Santa Cruz, CA, USA). The membranes were further treated with Super Signal West Pico chemiluminescent substrate (Thermo Fisher Scientific, Waltham, MA, USA) and detected by the Typhoon Trioe Imager (GE Healthcare, Chicago, IL, USA). Protein bands were quantified by densitometry using Image Quante software (Quantity one 4.61, Bio-rad, Hercules, CA, USA).

\section{Concentrations of gastrointestinal hormones and immunoglobulins in jejunal mucosa}

The concentrations of gastrointestinal hormones including substance $\mathrm{P}(\mathrm{SP})$, vasoactive intestinal peptide (VIP) and the immunoglobulins including secretory immunoglobulin A (SIgA), immunoglobulin G (IgG), immunoglobulin M (IgM) in jejunal mucosa were measured using the relative enzymelinked immune sorbent assay kit (R\&D Systems China Co., Ltd. Shanghai, China). The operations were executed according to the instructions of the manufacturer.

\section{Statistical analysis}

Statistics were analyzed by one-way ANOVA using the SAS program (version 8.02, SAS Institute Inc., Cary, NC, USA). Significant differences among treatment means were separated by Duncan's multiple range tests. The data were analysed with pen as the experimental unit $(n=3$, the means of two pigs per pen were used to represent the pens). Less than $0.05 \mathrm{p}$ value was used to indicate statistical significance.

\section{RESULTS}

\section{Small intestinal histomorphology}

Data on the small intestinal structure were summarized in Table 3, compared with the control ( $0.62 \% \mathrm{Ala})$, dietary AlaGln supplementation increased the villi height of duodenum and jejunum in the piglets $(\mathrm{p}<0.05)$, up-regulated the ratio of villi height to crypt depth of duodenum and ileum $(\mathrm{p}<0.05)$,
Table 3. Effects of dietary Ala-GIn and GIn supplementation on intestinal morphology of piglets $(n=3)$

\begin{tabular}{lccccc}
\hline \multirow{2}{*}{ Items } & \multicolumn{3}{c}{ Groups } & & \\
\cline { 2 - 4 } & Control & Ala-Gln & Gln & & p-value \\
\hline Duodenum & & & & & \\
$\quad$ Villus height $(\mu \mathrm{m})$ & $474^{\mathrm{b}}$ & $499^{\mathrm{a}}$ & $480 \mathrm{~b}$ & 2.99 & 0.015 \\
$\quad$ Crypt depth $(\mu \mathrm{m})$ & 257 & 240 & 252 & 3.80 & 0.197 \\
$\quad$ Villus height:Crypt depth & $1.86^{\mathrm{c}}$ & $2.08^{\mathrm{a}}$ & $1.91^{\mathrm{b}}$ & 0.04 & 0.035 \\
Jejunum & & & & & \\
$\quad$ Villus height $(\mu \mathrm{m})$ & $399^{\mathrm{c}}$ & $459^{\mathrm{a}}$ & $441^{\mathrm{b}}$ & 6.17 & 0.014 \\
$\quad$ Crypt depth $(\mu \mathrm{m})$ & $178^{\mathrm{a}}$ & $1.69^{\mathrm{b}}$ & $172^{\mathrm{b}}$ & 1.39 & 0.036 \\
$\quad$ Villus height:Crypt depth & 2.25 & 2.72 & 2.57 & 0.05 & 0.050 \\
Ileum & & & & & \\
$\quad$ Villus height $(\mu \mathrm{m})$ & 316 & 333 & 322 & 2.51 & 0.072 \\
$\quad$ Crypt depth $(\mu \mathrm{m})$ & $176^{\mathrm{a}}$ & $158^{\mathrm{c}}$ & $167^{\mathrm{b}}$ & 2.11 & 0.027 \\
$\quad$ Villus height:Crypt depth & $1.80^{\mathrm{c}}$ & $2.11^{\mathrm{a}}$ & $1.93^{\mathrm{b}}$ & 0.02 & 0.033 \\
\hline
\end{tabular}

Ala-Gln, alanyl-glutamine; Gln, glutamine; SEM, standard error of the means.

$a, b, c$ Mean values in the same target of different treatments were significantly different $(p<0.05)$.

decreased the crypts depth of jejunum and ileum $(\mathrm{p}<0.05)$. In comparison with the control, Gln supplementation significantly increased the villi height of jejunum, up-regulated the ratio of villi height to crypt depth in the duodenum and ileum on piglets $(p<0.05)$, reduced the crypts depth in the jejunum and ileum $(\mathrm{p}<0.05)$.

Relative mRNA expressions of epidermal growth factor, insulin-like growth factor 1 , and their receptors in jejunal mucosa

Compared with the control ( $0.62 \% \mathrm{Ala})$, dietary Ala-Gln supplementation increased the mRNA expressions of epidermal growth factor (EGF), epidermal growth factor receptor (EGFR), insulin-like growth factor 1 (IGF-1), and insulin-like growth factor 1 receptor (IGF-1R) in the jejunal mucosa $(\mathrm{p}<0.05$; Figure 1). In addition, Gln supplementation increased the mRNA expressions of EGF, IGF-1, and IGF-1R in the jejunal mucosa $(p<0.05)$ compared with the control, but there was no significant difference in the mRNA expression of EGFR in the jejunal mucosa.

\section{Relative mRNA expressions of tight junction proteins in jejunal mucosal}

Dietary Ala-Gln supplementation increased the mRNA expressions of jejunal mucosal occludin, claudin-1 and ZO-1 in piglets $(\mathrm{p}<0.05$; Figure 2$)$ compared with the control $(0.62 \% \mathrm{Ala})$. Relatively, Gln supplementation increased the mRNA expressions of occludin and ZO- 1 in the jejunal mucosa $(p<0.05)$ compared with those in control, whereas, Gln supplementation did not affect the mRNA expression of claudin-1 in the jejunal mucosa.

Relative protein levels of tight junction proteins in jejunal 
A

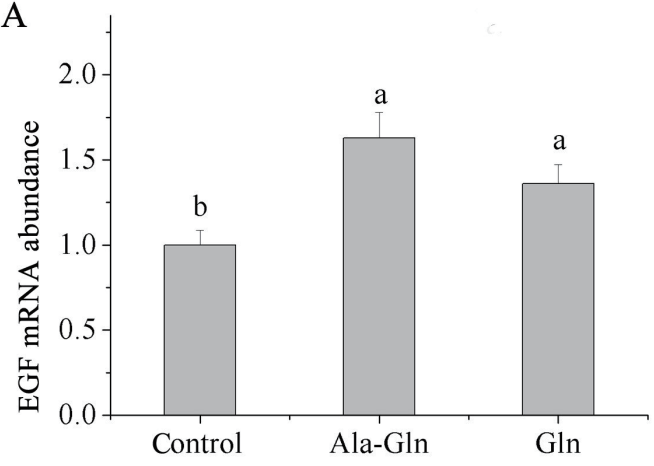

$\mathrm{C}$

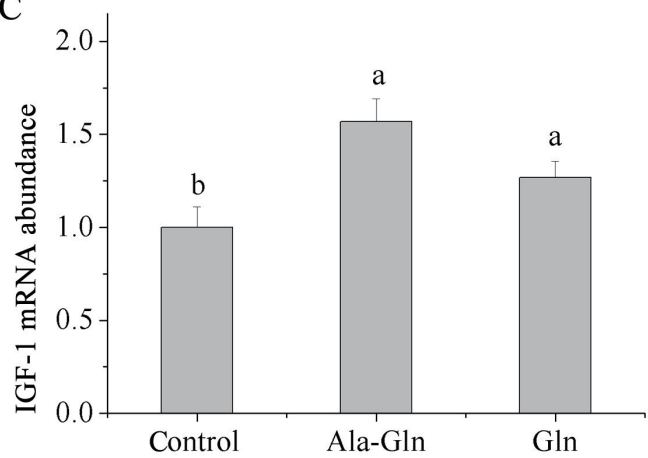

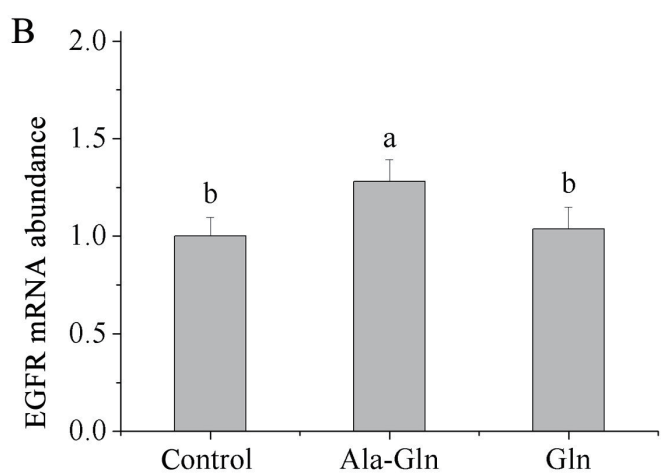

$\mathrm{D}$

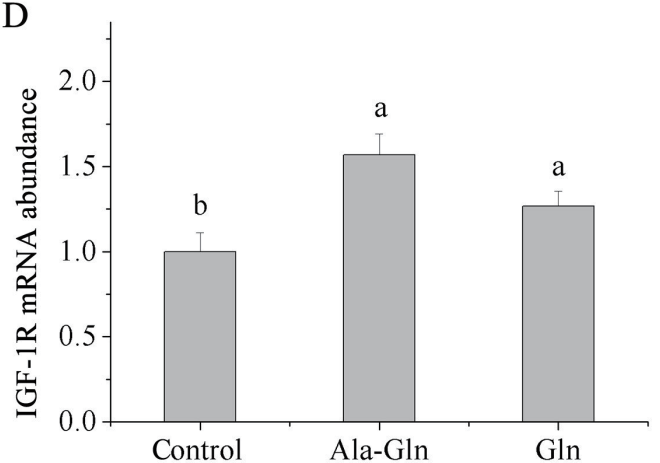

Figure 1. Effects of dietary Ala-GIn and Gln supplementation on the mRNA expressions of cell proliferation related factors in the jejunum mucosa of piglets ( $\mathrm{n}=3$ ). Values are means with their stand errors represented by vertical bars. ${ }^{a, b}$ Mean values in the same target of different treatments were significantly different $(p<0.05)$. Ala-Gln, alanyl-glutamine; EGF, epidermal growth factor; EGFR, epidermal growth factor receptor; GIn, glutamine; IGF-1, insulin-like growth factor 1; IGF-1R, insulin-like growth factor 1 receptor.

A

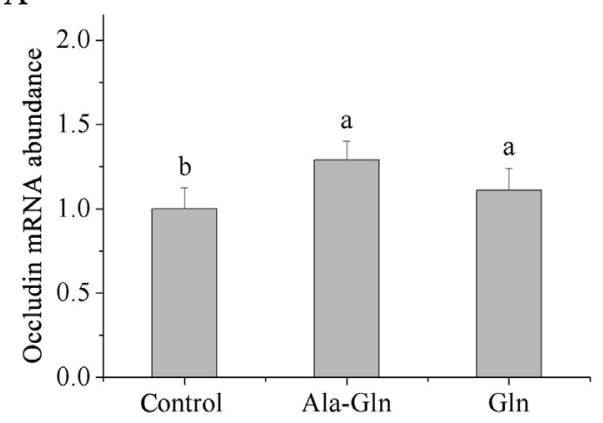

B

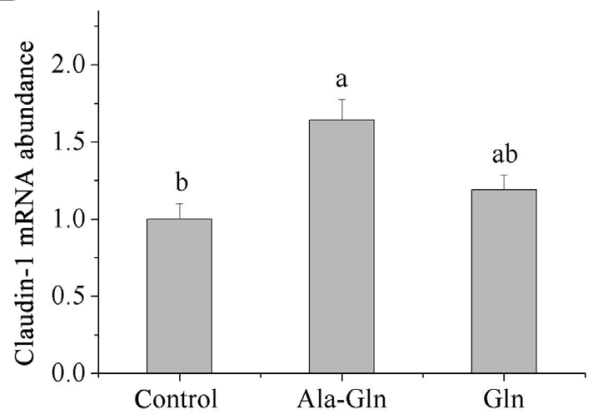

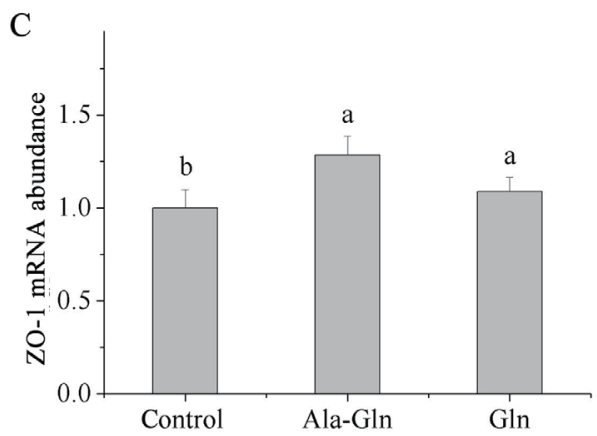

Figure 2. Effects of dietary Ala-GIn and Gln supplementation on the mRNA expression of tight junction proteins in the jejunum mucosa of piglets $(n=3)$. Values are means with their stand errors represented by vertical bars. ${ }^{a, b}$ Mean values in the same target of different treatments were significantly different ( $\left.p<0.05\right)$. Ala-Gln, alanyl-glutamine; Gln, glutamine; Z0-1, zonula occludens protein-1. 
A

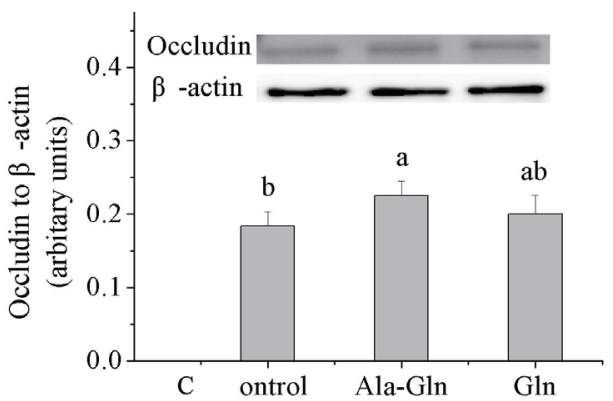

B

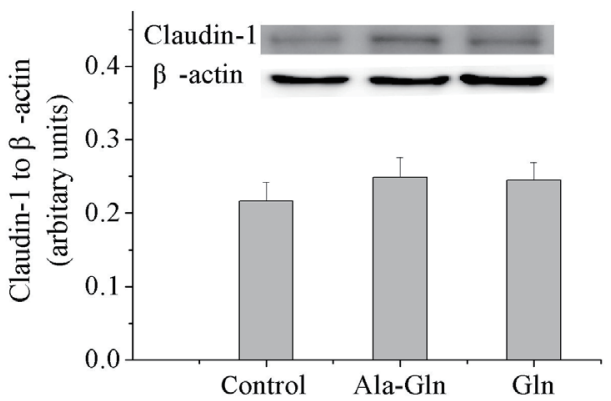

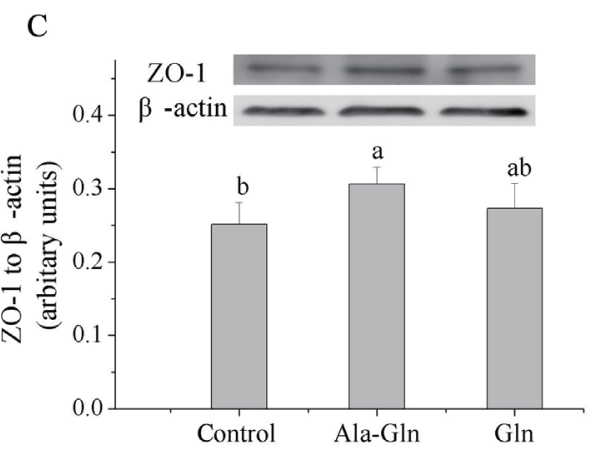

Figure 3. Effects of dietary Ala-Gln and Gln supplementation on the protein expression of tight junction proteins in the jejunum mucosa of piglets $(n=3)$. Values are means with their stand errors represented by vertical bars. ${ }^{a, b}$ Mean values in the same target of different treatments were significantly different $(p<0.05)$. Ala-Gln, alanyl-glutamine; Gln, glutamine; Z0-1, zonula occludens protein-1.

\section{mucosa}

Compared with the control ( $0.62 \% \mathrm{Ala})$, dietary Ala-Gln supplementation increased the protein levels of occludin and ZO-1 $(\mathrm{p}<0.05$; Figure 3$)$ in the jejunal mucosa, however, there was no difference in the protein level of claudin-1 of the jejunal mucosa. By contrast, Gln supplementation had no effect on the protein levels of occludin, claudin-1, or ZO-1 in the jejunal mucosa compared with the control.

\section{The number of goblet cells in small intestine}

As Table 4 shown, the number of goblet cells in the duodenum and ileum epithelium were increased by Ala-Gln supplementation $(\mathrm{p}<0.05)$ compared with the control $(0.62 \% \mathrm{Ala})$, there was no difference in the number of goblet cells of jejunum be-

Table 4. Effects of dietary Ala-Gln and Gln supplementation on the number of goblet cells in small intestinal epithelium in of piglets $(n=3)$

\begin{tabular}{|c|c|c|c|c|c|}
\hline \multirow{2}{*}{ Items } & \multicolumn{3}{|c|}{ Groups } & \multirow{2}{*}{ SEM } & \multirow{2}{*}{$\mathrm{p}$-value } \\
\hline & Control & Ala-Gln & Gln & & \\
\hline \multicolumn{6}{|c|}{ Goblet cells (piece/100 pieces) } \\
\hline Duodenum & $2.58^{\mathrm{b}}$ & $2.80^{\mathrm{a}}$ & $2.71^{\mathrm{a}}$ & 0.03 & 0.021 \\
\hline Jejunum & 4.47 & 4.69 & 4.60 & 0.04 & 0.057 \\
\hline Ileum & $5.39^{b}$ & $5.65^{\mathrm{a}}$ & $5.42^{b}$ & 0.05 & 0.040 \\
\hline
\end{tabular}

Ala-Gln, alanyl-glutamine; Gln, glutamine; SEM, standard error of the means.

$a, b$ Mean values in the same target of different treatments were significantly different $(p<0.05)$. tween the Ala-Gln supplementation group and control group. On the other hand, Gln supplementation increased the number of goblet cells in the duodenum compared with the control $(\mathrm{p}<0.05)$, however, no effect of which was observed in the jejunum or ileum.

Relative mRNA expressions of mucin in jejunal mucosa As presented in Figure 4, compared with the control ( $0.62 \% \mathrm{Ala})$, the diets supplemented with Ala-Gln and Gln increased the mRNA expression of mucin 2 (MUC2) in the jejunal mucosa $(\mathrm{p}<0.05)$. However, neither Ala-Gln nor Gln supplementation significantly affected the mRNA expression of mucin 1 (MUC1) in the jejunal mucosa compared to the control.

\section{Concentrations of gastrointestinal hormones in jejunal mucosa}

As shown in Table 5, the concentrations of SP and VIP in the jejunal mucosa were increased by dietary Ala-Gln supplementation compared with the control $(0.62 \% \mathrm{Ala})(\mathrm{p}<0.05)$. In comparison, Gln supplementation increased the concentration of VIP in the jejunal mucosa ( $\mathrm{p}<0.05)$ compared with the control, the concentration of SP in the jejunal mucosa did not differ between Gln supplementation group and the control group.

Concentrations of immunoglobulins in jejunal mucosa As shown in Table 6, compared with the control ( $0.62 \%$ Ala), 
A

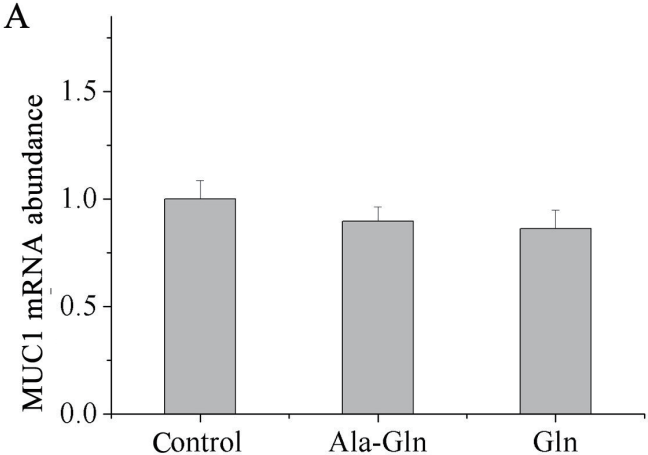

B

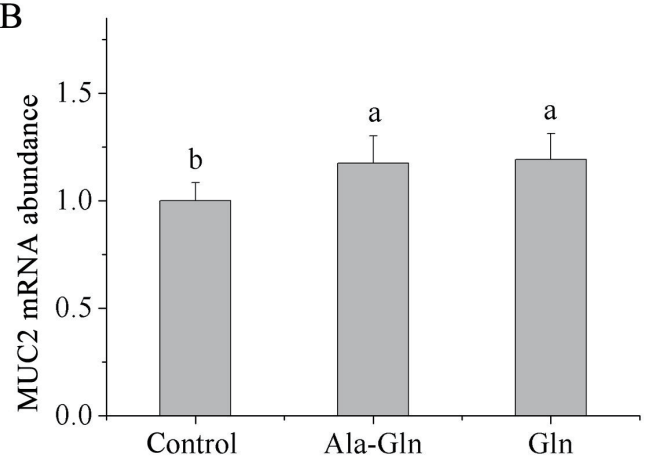

Figure 4. Effects of dietary Ala-GIn and GIn supplementation on the mRNA expression of MUC1 and MUC2 in the jejunum mucosa of piglets $(n=3)$. Values are means with their stand errors represented by vertical bars. ${ }^{a, b}$ Mean values in the same target of different treatments were significantly different ( $\left.p<0.05\right)$. Ala-Gln, alanyl-glutamine; Gln, glutamine; MUC1, mucin 1; MUC2, mucin 2.

dietary Ala-Gln supplementation increased the concentrations of SIgA and IgG in the jejunal mucosa $(\mathrm{p}<0.05)$. In comparison with the control, Gln supplementation increased the concentration of SIgA in the jejunal mucosa $(\mathrm{p}<0.05)$, whereas, the concentration of IgM in the jejunal mucosa did not differ among the three treatment groups.

\section{DISCUSSION}

The intestine is not only the crucial organ for digestion and absorption of nutrients in piglets, but also an important component of the body's immune system. During the early growth of piglets the development of small intestine is imperfect and sensitive, consequently, weaning will often lead to the common failings such as functional disorder and structural damage of intestine. The results of Hsu showed that the villi height of the Gln supplementation (1\% and 2\%) groups tended higher than the control group in duodenum and jejunum [12]. Bartell and Batal found that chicks fed diets with $1 \%$ Gln had heavier intestinal relative weights and longer intestinal villi compared with the control [13]. In the present experiment, Gln supplementation increased the villi height of jejunum and reduced the crypts depth of jejunum and ileum. Braga-Neto's experiment found that dietary supplemented with Ala-Gln increased the height of intestinal villi in mouse [14]. Our present results indicated that dietary Ala-Gln supplementation increased the

Table 5. Effects of dietary Ala-Gln and Gln supplementation on the concentrations of $\mathrm{SP}$ and VIP in the jejunum mucosa of piglets $(n=3)$

\begin{tabular}{lccccc}
\hline \multirow{2}{*}{ Items } & \multicolumn{3}{c}{ Groups } & \multirow{2}{*}{ SEM } & p-value \\
\cline { 2 - 4 } & Control & Ala-Gln & Gln & & \\
\hline SP (ng/g of protein) & $9.09^{\mathrm{b}}$ & $11.53^{\mathrm{a}}$ & $9.42^{\mathrm{b}}$ & 0.40 & 0.019 \\
VIP (ng/g of protein) & $2.52^{\mathrm{b}}$ & $2.87^{\mathrm{a}}$ & $2.83^{\mathrm{a}}$ & 0.05 & 0.034 \\
\hline
\end{tabular}

Ala-GIn, alanyl-glutamine; Gln, glutamine; SP, substance P; VIP, vasoactive intestinal peptide; SEM, standard error of the means.

$a, b$ Mean values within a row with different superscript letters were significantly different $(p<0.05)$ villi height of duodenum and jejunum, decreased the crypt depth of jejunum and ileum, which was consistent with previous study. Carneiro-Filho' study reported that Ala-Gln accelerated the intestinal recovery compared with 5-FU-treated controls [15]. Comparing the results between Ala-Gln group and Gln group in our study, we found that Ala-Gln supplementation increased the villi height of duodenum and jejunum, up-regulated the ratio of villi height to crypt depth of duodenum and ileum than those in Gln supplementation. The results mentioned above suggest that dietary Ala-Gln supplementation was more effective to maintain the intestinal structural integrity of the piglets than Gln supplementation group, and it may be ascribed to that Ala-Gln was more stable and dissolvable than the free Gln.

Piglets have to obtain some important active substances (EGF, Gln, growth hormone, IGF-1, etc) from milk during the earlier age, whereas, this source will be interrupted by weaning, which may producing a negative influence on the small intestinal mucosal structure [16]. In terms of that, many intestinal epithelial cells have the ability to secrete EGF, IGF-1, etc in the process of cell proliferation and structural restitution. In this study, dietary Gln supplementation increased the mRNA expressions of EGF and IGF-1 in jejunal mucosa of piglets, and their mRNA expressions were higher with Ala-Gln supplementation. BragaNeto's experiment reported that Gln and Ala-Gln supple-

Table 6. Effects of dietary Ala-GIn and Gln supplementation on the concentrations of $S \lg A, \lg G$, and $\lg M$ in the jejunum mucosa of piglets $(n=3)$

\begin{tabular}{lccccc}
\hline \multirow{2}{*}{ Items } & \multicolumn{3}{c}{ Groups } & \multirow{2}{*}{ SEM } & p-value \\
\cline { 2 - 4 } & Control & Ala-Gln & Gln & & \\
\hline SlgA ( $\mu \mathrm{g} / \mathrm{mg}$ of protein) & $5.82^{\mathrm{b}}$ & $6.11^{\mathrm{a}}$ & $6.00^{\mathrm{a}}$ & 0.18 & 0.012 \\
$\operatorname{lgG}(\mathrm{mg} / \mathrm{mg}$ of protein) & $0.22^{\mathrm{b}}$ & $0.25^{\mathrm{a}}$ & $0.23^{\mathrm{b}}$ & 0.02 & 0.026 \\
IgM (mg/mg of protein) & 0.17 & 0.18 & 0.17 & 0.03 & 0.128 \\
\hline
\end{tabular}

Ala-Gln, alanyl-glutamine; Gln, glutamine; SIgA, secretory immunoglobulin A; IgG, immunoglobulin G; IgM, immunoglobulin M; SEM, standard error of the means.

$a, b$ Mean values within a row with different superscript letters were significantly different $(p<0.05)$. 
mentation improved cell proliferation and migration in IEC-6 cells previously treated with 5-fluorouracil [17]. The functions of EGFR and IGF-1R are similar, and they are the key receptors of EGF and IGF-1 in regulating cells proliferation and differentiation through mitogen-activated protein kinase (MAPK) or phosphatidylinositol-3-kinase (PI3K)/Akt pathways [18]. In the present study, dietary Ala-Gln supplementation increased the mRNA expressions of EGFR and IGF-1R in jejunal mucosa of piglets, and Gln supplementation also increased the mRNA expressions of IGF-1R in jejunal mucosa, but had no significant effect on the mRNA expression of EGFR in the jejunal mucosa. These results reminded that Ala-Gln and Gln could accelerate enterocyte proliferation and promote the functions of the intestinal mucosa physical barrier, and further signified that Ala-Gln was more beneficial enhancing the intestinal mucosa physical barrier than free Gln.

Tight junctions are located in the top of the intercellular structure, which play a critical role in regulating the paracellular permeability and cells polarity of the intestinal epithelium. The tight junctions are composed of transmembrane proteins, including occludin, claudins, tricellulin and junctional adhesion molecules, which may interact with the scaffold proteins such as ZO-1, ZO-2, ZO-3, etc to form the macromolecular compounds and anchor to the actin cytoskeleton on the membrane surface of the adjacent epithelial cells [19]. The disruption of tight junctions is an initial event and associated with the pathogenesis of many gastrointestinal diseases. Glutamine is considered to be the most important nutrient for healing of 'leaky gut syndrome', because Gln is the preferred fuel for enterocyte proliferation. Nan indicated that the deprivation of Gln decreased claudin-1, occludin, and ZO-1 protein levels and caused a disappearance of peri-junctional claudin-1 in Caco-2 cells [20]. Furthermore, Beutheu reported that Gln could improve the intestinal barrier function and increase the protein expression of the tight junctions in mice [21]. In addition, $\mathrm{Li}$ and Neu's experiment showed that Gln could regulate intercellular junction integrity and tight junction proteins through the PI3K/Akt signaling pathway. The integrity of the intestinal epithelial cells and the structure of intercellular junction was interactional, and Gln regulated intercellular tight junction integrity probably benefits from the intestinal epithelial cells proliferation. The present results showed that dietary Ala-Gln and Gln supplementation increased the mRNA and protein expressions of tight junctions, and the effects of Ala-Gln supplementation were better than the Gln supplementation. It indicated that Ala-Gln supplementation was beneficial to maintain paracellular permeability, and could promote the functions of intestinal mucosa physical barrier.

Goblet cells, which exist widely among the mucosal surface and scatter in the epithelial layer, have been implicated in the secretion of mucins [22]. There are many kinds of mucins and most recent research has been focused on MUC1 and MUC2.
MUC1 is the membrane-bound mucin located at the surface of epithelial cells which can promote the mucosal layer adhered to the epithelial cells. MUC2 is the secretory mucin which is the major component of mucin in intestinal mucus. The mucins are secreted by goblet cells, and then mix with water and electrolytes on the mucosal surface to form the chemical barrier upon the intestinal epithelium, which can protect the intestinal mucosa from chemical and mechanical damage [23]. In the present study, dietary Ala-Gln supplementation increased the number of intestinal goblet cells in the duodenum and ileum and up-regulated the mRNA expression of MUC2 in the jejunal mucosa. Similarly, Gln supplementation also improved the number of goblet cells in duodenum and motivated the mRNA expression of MUC2 in jejunal mucosa. The possible reason may be that Ala-Gln and Gln stimulated the intestinal crypt stem cells to proliferate and translate into goblet cells, so as to arouse the secretion of mucins, which were beneficial to strengthen the chemical barrier stability and diminish the intestinal mucosa damage.

The SP is an 11-amino-acid neuropeptide member of the tachykinin family, which localizes in the central nervous system, enteric nerves, immune cells and sensory neurons. Neurokinin-1 receptor (NK-1R) is the high-affinity receptor of SP. The SP can adjust the intestinal reactions including transfer the signal of algesia in the nervous system, regulate motility of the gastrointestinal tract, mucosal permeability and inflammation once it connects with NK-1R [24]. Muangman reported that SP ameliorated the impaired wound healing in nitric oxide synthase null mice by increasing macrophages density in the wounds. Koon's study showed that the interactions of SP and NK-1R could stimulate colonic epithelial cell proliferation [25]. The results in our present study showed that dietary Ala-Gln supplementation increased the concentration of SP in the jejunal mucosa. It suggested that Ala-Gln supplementation was beneficial to enhance the proliferation of the intestinal immune cells and the intestinal immune response capacity. The VIP is one of the best-studied immunoregulatory neuropeptides, which plays a role in two-way signal transmission in the nervous system and immune system [26]. The VIP will interact with its receptors which locate on the surface of the macrophages, and then modulate both innate and adaptive immunity, activate $\mathrm{T}$ cells proliferation and differentiation [27]. The present results showed that dietary Ala-Gln and Gln supplementation increased the concentration of VIP in jejunal mucosa, which suggested that Ala-Gln and Gln might have improved the hormonal regulation of intestinal functions and promoted the immune protection of the intestine in piglets.

Intestinal immune functions development deficiency will be a factor affecting piglet growth and development during young age period. Moreover, segregating and weaning stress will disrupt the intestinal functions and arouse intestinal inflammation and activate the immune cell proliferation. Immuno- 
globulins are primarily secreted by lymphoid cells and participate in actuating both humoral and cellular immune reactions. SIgA is the most important member among the immunoglobulins and is secreted by lymphatic B cells and plays an essential immune role in preventing pathogenic agents colonizing the intestinal epithelium, as well as modulating the inflammatory response to maintain the intestinal homeostasis [28]. In addition, IgG and IgM are also involved in immune responses in the intestine $[29,30]$. The Gln is a primary fuel to be utilized by intraepithelial lymphocytes. In the present study, the results showed that Gln supplementation increased the concentration of SIgA in jejunal mucosa. Furthermore, dietary Ala-Gln supplementation increased the concentrations of SIgA and IgG in jejunal mucosa. It is probable that Ala-Gln and Gln could improve the secretion of immunoglobulins in intestinal mucosa and enhance the mucosal immune barrier function through promoting the intestinal lymphocyte proliferation and development.

\section{CONCLUSION}

Dietary Ala-Gln supplementation could be beneficial to maintain the small intestinal health and promote the intestinal development of piglets through enhancing the physical, chemical and immune barriers in the intestinal mucosa.

\section{CONFLICT OF INTEREST}

We certify that there is no conflict of interest with any financial organization regarding the material discussed in the manuscript.

\section{ACKNOWLEDGMENTS}

This research was supported by the National Key Basic Research Program of China (2013CB127306).

\section{REFERENCES}

1. Viggiano D, Ianiro G, Vanella G, et al. Gut barrier in health and disease: focus on childhood. Eur Rev Med Pharmaco 2015;19: 1077-85.

2. Nalle SC, Turner JR. Intestinal barrier loss as a critical pathogenic link between inflammatory bowel disease and graft-versus-host disease. Mucosal Immunol 2015;8:720-30.

3. Wu GY. Recent advances in swine amino acid nutrition. J Anim Sci Biotechnol 2010;1:118-30.

4. Rogero MM, Tirapegui J, Pedrosa RG, de Castro IA, de Oliveira Pires IS. Effect of alanyl-glutamine supplementation on plasma and tissue glutamine concentrations in rats submitted to exhaustive exercise. Nutrition 2006;22:564-71.

5. Zhang BL, Lin M, Yu CN, et al. Alanyl-glutamine supplementation regulates $\mathrm{mTOR}$ and ubiquitin proteasome proteolysis signaling pathways in piglets. Nutrition 2016;32:1123-31.
6. Haynes TE, Li P, Li X, et al. L-Glutamine or L-alanyl-L-glutamine prevents oxidant or endotoxin-induced death of neonatal enterocytes. Amino acids 2009;37:131-42.

7. Wang J, Chen L, Li P, et al. Gene expression is altered in piglet small intestine by weaning and dietary glutamine supplementation. J Nutr 2008;138:1025-32.

8. Committee on Nutrient Requirements of Swine, National Research Council. Nutrient requirements of swine. 11th ed. Washington, DC: National Academy Press; 2012.

9. Xiong B, Pang Z, Luo Q. Tables of feed composition and nutritive values in China. Chin Feed 2012; 21:33-44 (In Chinese).

10. AOAC International. Official methods of analysis of AOAC International. 17th ed. Gaithersburg, MD: AOAC International; 2000.

11. Livak KJ, Schmittgen TD. Analysis of relative gene expression data using real-time quantitative PCR and the $2^{-\Delta \Delta C T}$ method. Methods 2001;25:402-8.

12. Hsu CB, Huang HJ, Wang CH, Yen HT, Yu B. The effect of glutamine supplement on small intestinal morphology and xylose absorptive ability of weaned piglets. Afr J Biotechnol 2010;9: 7003-8.

13. Bartell SM, Batal AB. The effect of supplemental glutamine on growth performance, development of the gastrointestinal tract, and humoral immune response of broilers. Poult Sci 2007;86: 1940-7.

14. Braga-Neto MB, Oliveira BM, Rodrigues RS, et al. Protective effects of alanyl-glutamine supplementation against nelfinavirinduced epithelial impairment in IEC-6 cells and in mouse intestinal mucosa. Cancer Biol Ther 2012;13:1482-90.

15. Carneiro-Filho BA, Oriá RB, Rea KW, et al. Alanyl-glutamine hastens morphologic recovery from 5-fluorouracil-induced mucositis in mice. Nutrition 2004;20:934-41.

16. Xu RJ. Development of the newborn GI tract and its relation to colostrum/milk intake: a review. Reprod Fert Dev 1996;8:35-48.

17. Braga-Neto, MB, Warren CA, Oria, RB, et al. Alanyl-glutamine and glutamine supplementation improves 5-fluorouracil-induced intestinal epithelium damage in vitro. Digest Dis Sci 2008;53: 2687-96.

18. Chun KH, Jerome WK, Sun SH, et al. Effects of deguelin on the phosphatidylinositol 3-Kinase/Akt pathway and apoptosis in premalignant human bronchial epithelial cells. J Natl Cancer I 2003;95:291-302.

19. Van Itallie CM, Anderson JM. Claudins and epithelial paracellular transport. Annu Rev Physiol 2006;68:403-29.

20. Nan L, Lewis P, Samuelson D, Liboni K, Neu J. Glutamine regulates Caco-2 cell tight junction proteins. Am J Physiol-Gastr L 2004; 287:G726-G33.

21. Beutheu S, Ouelaa W, Guérin C, et al. Glutamine supplementation, but not combined glutamine and arginine supplementation, improves gut barrier function during chemotherapy-induced intestinal mucositis in rats. Clin Nutr 2014;33:694-701.

22. Patel KK, Miyoshi H, Beatty WL, et al. Autophagy proteins control goblet cell function by potentiating reactive oxygen species prod- 
uction. Embo J 2013;32:3130-44.

23. Khan W. Physiological changes in the gastrointestinal tract and host protective immunity: learning from the mouse-Trichinella spiralis model. Parasitology 2008;135:671-82.

24. Koon HW, Pothoulakis C. Immunomodulatory properties of substance P: the gastrointestinal system as a model. Ann NY Acad Sci 2006;1088:23-40.

25. Koon HW, Zhao D, Zhan Y, Moyer MP, Pothoulakis C. Substance $\mathrm{P}$ mediates antiapoptotic responses in human colonocytes by Akt activation. P Nati Acad Sci USA 2007;104:2013-18.

26. Gomariz RP, Juarranz Y, Abad C, et al. VIP-PACAP system in immunity: new insights for multitarget therapy. Ann NY Acad
Sci 2006;1070:51-74.

27. Jimeno R, Gomariz RP, Gutiérrez-Cañas I, et al. New insights into the role of VIP on the ratio of T-cell subsets during the development of autoimmune diabetes. Immunol Cell Biol 2010;88:734-45.

28. Bellussi L, Cambi J, Passali D. Functional maturation of nasal mucosa: role of secretory immunoglobulin A (SIgA). Multidiscip Resp Med 2013;8:46.

29. Jiang D, Ge J, Liao Q, et al. IgG and IgA with potential microbialbinding activity are expressed by normal human skin epidermal cells. Int J Mol Sci 2015;16:2574-90.

30. Gronwall C, Vas J, Silverman GJ. Protective roles of natural IgM antibodies. Front Immunol 2012; 3:66. 